\title{
Supplementing volatile-flavour herbal-extract mixture to the diet of sows and their weaned offspring improves the growth performance of weaned piglets
}

\author{
D.X. Dang ${ }^{1}$, K.D. Han ${ }^{2,3}$ and I.H. Kim ${ }^{1 *}$ \\ ${ }^{1}$ Department of Animal Resource \& Science, Dankook University, Cheonan 31116, Republic of Korea; ${ }^{2}$ Department \\ of Microbiology, College of Science \& Technology, Dankook University, Cheonan 31116, Republic of Korea; ${ }^{3}$ Center for \\ Bio-Medical Engineering Core Facility, Dankook University, Cheonan 31116, Republic of Korea; inhokim@dankook.ac.kr
}

Received: 29 June 2021 / Accepted: 10 August 2021

(c) 2021 D.X. Dang et al.

RESEARCH ARTICLE

PIGS

\begin{abstract}
A volatile herbal extract (VHE), consisting of $150 \mathrm{~g} / \mathrm{kg}$ anethole, $15 \mathrm{~g} / \mathrm{kg}$ bebaudioside A, $2.1 \mathrm{~g} / \mathrm{kg}$ thymol, $2.0 \mathrm{~g} / \mathrm{kg}$ eugenol and $2.3 \mathrm{~g} / \mathrm{kg}$ cinnamic aldehyde, was fed to sows and their weaned offspring to evaluate its effect on the reproductive performance of sows and the growth performance of weaned piglets. A total of 18 sows (Landrace $\times$ Yorkshire) were randomly assigned to dietary treatments based on average parity (1.78) with nine replicates per treatment. The feeding period was 35 days, from $\mathrm{d} 7$ before farrowing to $\mathrm{d} 7$ after weaning. The lactation period was $21 \mathrm{~d}$. A total of 96 piglets were randomly selected from each sow treatment group and allocated to 24 replicate pens with four pigs (mixed sex) per pen. The feeding period of weaned piglets was 35 days (phase 1, days 1-7; phase 2 , days 8-21; phase 3, days 22-35). Dietary treatments in sows and weaned piglets consisted of a basal control diet with or without $500 \mathrm{mg} / \mathrm{kg}$ VHE. The data showed that VHE supplementation had no effect on the reproductive performance of sows, but improved the growth performance of weaned piglets, in which the increase of average daily gain during days 1-7 $(P=0.006)$ and 1-35 $(P=0.032)$ and feed efficiency during days 22-35 $(P=0.026)$ and 1-35 $(P=0.020)$ in weaned piglets were observed. Therefore, supplementing VHE to the diet of sows and their weaned offspring was beneficial to the growth performance of weaned piglets.
\end{abstract}

Keywords: swine, herbal extract, growth performance, prenatal flavour exposure

\section{Introduction}

Weaning is a challenging period in the modern swine industry and correct feeding and gut function is important to growth performance and welfare of the piglets (ValLaillet et al., 2016). Charal et al. (2016) have shown that feeding sows and their weaned offspring fed plant extracts can improve performance and facilitate weaning transition (Oostindjer et al., 2011). However, information on supplementing mixed volatile herbal extracts (VHE) to the diet of sows and their weaned offspring is still limited.

The mixed VHE used in this study had a long-term odour and was composed of anethole, rebaudioside A, thymol, eugenol, and cinnamic aldehyde. Positive effects of this mix on the growth and productive performance of pigs have been previously shown (Yan and Kim, 2012; Wang et al., 2014; Diao et al., 2015; Williams et al., 2017; Yi et al., 2021). The following trial determined whether supplementing VHE to the diet of sows during late-gestation and lactation and their weaned offspring could improve the reproductive performance of sows and the growth performance of weaned piglets.

\section{Material and methods}

The experimental protocol (DK-2-1913) was approved by the Animal Care and Use Committee of Dankook University (Cheonan, South Korea). The care and treatment of the 
sows were according to the animal welfare legislation (Federation of Animal Science Societies, 2010).

\section{Volatile herbal extract treatment}

The VHE used in this study is obtained from a commercial company (Molimen, Barcelona, Spain / Nawbio Co., Ltd, Yongin, Korea). It consisted of $150 \mathrm{~g} / \mathrm{kg}$ anethole, $15 \mathrm{~g} / \mathrm{kg}$ bebaudioside A, $2.1 \mathrm{~g} / \mathrm{kg}$ thymol, $2.0 \mathrm{~g} / \mathrm{kg}$ eugenol, and $2.3 \mathrm{~g} / \mathrm{kg}$ cinnamic aldehyde. The combination of the above substances has long-term odour, which has been classified as a flavouring agent.

\section{Experiment design, animals and housing}

A total of 18 sows (Landrace $\times$ Yorkshire) were randomly assigned to two treatments based on average parity (1.78). There were nine replicates per treatment. The feeding period was $35 \mathrm{~d}$, from $\mathrm{d} 7$ before farrowing to $\mathrm{d} 7$ after weaning, with a lactation period of 21 days. After weaning, a total of 96 piglets were randomly selected from each group of sows and assigned to 24 replicate pens with four pigs (mixed sex) per pen. The feeding period of weaned piglets was 35 days (phase 11-7 d; phase 2 8-21 d; phase 3 22-35 d). Dietary treatments in sows and weaned piglets consisted of a basal diet with or without $500 \mathrm{mg} / \mathrm{kg}$ VHE. Dietary treatments were formulated to meet the recommendations of the NRC (2012) and provided in mash form (Table 1 and 2).

All sows were housed in a farrowing room on d 107 of gestation, which were equipped with auto-controlled heating and mechanical ventilation systems, with $2.20 \times 1.60 \mathrm{~m}$ area individually for the $35 \mathrm{~d}$ feeding period. Sows were fed $3.8 \mathrm{~kg} / \mathrm{d}$ of experimental feed from d 107 of gestation to farrowing and $\mathrm{d} 21$ after farrowing to $\mathrm{d} 7$ after weaning. During the lactation period ( $21 \mathrm{~d})$, daily feed allowance was increased to $7 \mathrm{~kg} / \mathrm{d}$. Experimental feed was provided ad libitum from troughs as three equal meals per day.

Cross-fostering of piglets took place within two days of parturition and occurred only among the same experimental treatment of sows. The number of piglets per sow ranged from nine to 11 piglets and the numbers of weaned piglets were recorded. Piglets did not receive creep feed during the lactation period, and were subjected to routine management practices from three days after birth, including teeth clipping and tail docking, and received $1 \mathrm{ml}$ iron dextran $(50 \mathrm{mg} / \mathrm{kg})$, and the male piglets were castrated.

In accordance with treatment group of the sows, 96 piglets that came from the same treatment were moved to an environment-controlled nursery barn allocated to 24 replicate pens with four pigs (mixed sex) per pen. The ambient temperature within the room was maintained
Table 1. Composition and nutrient levels of the experimental basal diet of sows (\%, as-fed basis).

$\begin{array}{lr}\text { Items } & \\ \text { Ingredients, \% } & 34.01 \\ \text { Corn } & 23.00 \\ \text { Wheat } & 2.00 \\ \text { Rice bran } & 8.31 \\ \text { Wheat bran } & 6.00 \\ \text { Soybean meal } & 12.96 \\ \text { Dehulled soybean meal } & 3.74 \\ \text { Soybean oil } & 2.00 \\ \text { Molasses } & 4.00 \\ \text { Bakery by product } & 1.23 \\ \text { Limestone } & 0.68 \\ \text { Di-calcium phosphate } & 0.50 \\ \text { Salt } & 0.05 \\ \text { Threonine, } 98 \% & 0.60 \\ \text { Lysine, } 25 \% & 0.12 \\ \text { Choline chloride, } 50 \% & 0.80 \\ \text { Vitamin/mineral mixture } 1 & 100.00 \\ \text { Total } & 14.82 \\ \text { Analysed composition, \% } & 16.30 \\ \text { Digestible energy, MJ/kg } & 6.70 \\ \text { Crude protein } & 5.00 \\ \text { Crude fat } & 3.60 \\ \text { Crude ash } & 0.75 \\ \text { Crude fibre } & 0.54 \\ \text { Calcium } & \end{array}$

1 Provided per kilogram of complete diet: vitamin A, 10,000 IU; vitamin D3, 2,000 IU; vitamin E, $48 \mathrm{IU}$; vitamin K3, $1.5 \mathrm{mg}$; riboflavin, $6 \mathrm{mg}$; niacin, $40 \mathrm{mg}$; d-pantothenic, $17 \mathrm{mg}$; biotin, $0.2 \mathrm{mg}$; folic acid, $2 \mathrm{mg}$; choline, $166 \mathrm{mg}$; vitamin $\mathrm{B} 6,2 \mathrm{mg}$; and vitamin B12, $28 \mu \mathrm{g}$; $\mathrm{Fe}$ (as FeSO4.7H2O), $90 \mathrm{mg}$; $\mathrm{Cu}$ (as CuSO4.5H2O), $15 \mathrm{mg}$; Zn (as ZnSO4), $50 \mathrm{mg}$; $\mathrm{Mn}$ (as MnO2), $54 \mathrm{mg}$; I (as $\mathrm{KI}), 0.99 \mathrm{mg}$; and $\mathrm{Se}$ (as Na2SeO3.5H2O), $0.25 \mathrm{mg}$.

at $30{ }^{\circ} \mathrm{C}$ for the first week and reduced by $1{ }^{\circ} \mathrm{C}$ per week subsequently. The humidity was around $60 \%$. The sows and piglets had free access to drinking water throughout the experimental period.

\section{Sampling and measurements}

The body weight and backfat thickness of sows were measured on $\mathrm{d} 107$ of gestation, $\mathrm{d} 1$ after farrowing, $\mathrm{d} 21$ after farrowing (weaning day), and $\mathrm{d} 7$ after weaning. A realtime ultrasound instrument (Piglot 105; SFK Technology, Herlev, Denmark) was used to determine the backfat thickness at the $6 \mathrm{~cm}$ from the mid-line at the $10^{\text {th }}$ rib. Daily feed consumption was recorded to calculate the average daily feed intake (ADFI) for each sow. The number of piglets per sow was recorded at farrowing and weaning to evaluate survival rate. The number of piglets born and alive was recorded to calculate the stillbirth rate at farrowing. The individual body weight of suckling piglets was recorded on the birth day and weaning day to calculate the average daily gain (ADG). The return-to-oestrus interval was measured by the method of Wang and Kim (2019) for each sow up to $7 \mathrm{~d}$ after weaning. Sows not expressing oestrus within the week after weaning were assigned a value of $7 \mathrm{~d}$ return to oestrus (Wang and Kim, 2019). 
Table 2. Composition and nutrient levels of the experimental basal diet of weaning pigs (\%, as-fed basis).

$\begin{array}{lrrr}\text { Items } & \text { Phase 1 (days 1-7) } & \text { Phase 2 (days 8-21) } & \text { Phase 3 (days 22-35) } \\ \text { Ingredients, \% } & & & 55.83 \\ \text { Extruded corn } & 37.29 & 47.80 & 24.00 \\ \text { Dehulled soybean meal } & 12.00 & 18.00 & - \\ \text { Fermented soybean meal } & 10.00 & 8.00 & 3.25 \\ \text { Fish meal } & 7.60 & 2.70 & 1.63 \\ \text { Soy oil } & 3.13 & 3.20 & 0.82 \\ \text { Di-calcium phosphate } & 1.24 & 1.34 & 2.00 \\ \text { Limestone } & 0.60 & 0.74 & 3.00 \\ \text { Sugar } & 3.00 & 2.00 & 3.00 \\ \text { Whey protein } & 11.00 & 8.00 & 0.48 \\ \text { Lactose } & 12.80 & 6.70 & 0.19 \\ \text { L-Lysine-HCL } & 0.35 & 0.46 & 0.20 \\ \text { DL-methionine } & 0.18 & 0.17 & 0.10 \\ \text { L-threonine } & 0.21 & 0.29 & 0.10 \\ \text { Choline chloride 50\% } & 0.10 & 0.10 & 0.20 \\ \text { Salt } & 0.10 & 0.10 & 0.20 \\ \text { Vitamin premix } & 0.20 & 0.20 & 100.00 \\ \text { Mineral premix } & 0.20 & 15.91 \\ \text { Total } & 0.20 & 100.00 & 18.50 \\ \text { Analysed composition, \% } & 100.00 & 16.33 & 4.20 \\ \text { Digestible energy, MJ/kg } & & 19.00 & 0.75 \\ \text { Crude protein } & 16.75 & 4.80 & 0.65 \\ \text { Crude fat } & 20.00 & 0.75 & 1.40 \\ \text { Calcium } & 5.40 & 0.65 & 0.42 \\ \text { Phosphorus } & 0.80 & 1.50 & 5.00 \\ \text { Lysine } & 0.70 & 0.45 & 12.00 \\ \text { Methionine } & 1.60 & & \end{array}$

1 Provided per kilogram of complete diet: vitamin A, 11,025 IU; vitamin D3, 1,103 IU; vitamin E, 44 IU; vitamin K, $4.4 \mathrm{mg}$; riboflavin, $8.3 \mathrm{mg}$; niacin, $50 \mathrm{mg}$; thiamine, $4 \mathrm{mg}$; d-pantothenic acid, $29 \mathrm{mg}$; choline, $166 \mathrm{mg}$ and vitamin B12, $33 \mu \mathrm{g}$.

2 Provided per kilogram of complete diet: Fe (as FeSO4·7H2O), 80 mg; Cu (as CuSO4·5H2O), 12 mg; Zn (as ZnSO4), 85 mg; Mn (as MnO2), 8 mg; I (as KI), 0.28 mg and $\mathrm{Se}$ (as Na2SeO3.5H2O), $0.15 \mathrm{mg}$.

After weaning, the body weight of weaned pigs was measured on days $1,7,21,35$ after weaning to calculate ADG. Pen-based feed consumption was calculated daily to measure the ADFI. Feed efficiency (as gain to feed ratio) was calculated using ADG and ADFI values.

\section{Statistical analysis}

All data were statistically analysed using the Student's t-test in SAS software (SAS version 9.4, 2014, SAS Inst. Inc., Cary, NC, USA). Each sow and each pen of weaned pigs were considered as the experimental unit. The data are presented as the means \pm standard deviation. Values of $P<0.05$ denoted statistical significance, while $0.05<P<0.10$ were considered as a trend.

\section{Results and discussion}

With regards to sows, supplementing VHE during lategestation and lactation had no effect on body weight, backfat thickness, average daily feed intake or litter size (Table 3), which agreed with the findings of Charal et al. (2016) and Moon (2017). They noted that dietary supplementation of aromatic substances only acted as a flavour, but did not affect the physical condition of the sows. Therefore, the reproductive performance of sows was considered not sensitive to the supplementation of VHE.
Table 3. Effects of supplementing a volatile herbal extract (VHE) mixture to the diet of sows on the reproductive performance of sows. ${ }^{1}$

\begin{tabular}{|c|c|c|c|}
\hline \multirow[b]{2}{*}{ Items } & \multicolumn{2}{|l|}{ VHE, $\mathrm{mg} / \mathrm{kg}$} & \multirow[t]{2}{*}{$P$-value } \\
\hline & 0 & 500 & \\
\hline Oestrus interval, days & $5.44 \pm 1.51$ & $4.44 \pm 0.53$ & 0.122 \\
\hline \multicolumn{4}{|l|}{ Body weight, $\mathrm{kg}$} \\
\hline Day 7 before farrowing & $210.30 \pm 22.66$ & $208.30 \pm 20.49$ & 0.845 \\
\hline Day 1 after farrowing & $187.50 \pm 22.15$ & $185.90 \pm 22.94$ & 0.883 \\
\hline Weaning day & $170.50 \pm 21.93$ & $170.70 \pm 23.22$ & 0.989 \\
\hline Day 7 after weaning & $172.80 \pm 21.74$ & $173.40 \pm 23.15$ & 0.960 \\
\hline \multicolumn{4}{|l|}{ Back-fat thickness, $\mathrm{mm}$} \\
\hline Day 7 before farrowing & $18.70 \pm 2.18$ & $18.13 \pm 1.60$ & 0.538 \\
\hline Day 1 after farrowing & $16.53 \pm 3.12$ & $16.21 \pm 2.01$ & 0.798 \\
\hline Weaning day & $14.49 \pm 2.96$ & $14.41 \pm 2.02$ & 0.949 \\
\hline Day 7 after weaning & $15.13 \pm 2.93$ & $15.11 \pm 2.10$ & 0.986 \\
\hline \multicolumn{4}{|c|}{ Average daily feed intake, $\mathrm{kg}$} \\
\hline Conception & $1.44 \pm 0.08$ & $1.46 \pm 0.06$ & 0.552 \\
\hline Lactation & $6.89 \pm 0.18$ & $6.94 \pm 0.14$ & 0.509 \\
\hline Breeding interval & $3.78 \pm 0.08$ & $3.80 \pm 0.13$ & 0.624 \\
\hline \multicolumn{4}{|l|}{ Litter size } \\
\hline Number of piglets born & $12.44 \pm 1.88$ & $12.67 \pm 1.94$ & 0.808 \\
\hline Number of piglets alive & $11.78 \pm 1.72$ & $12.00 \pm 1.80$ & 0.792 \\
\hline Survival rate, $\%$ & $94.90 \pm 6.99$ & $95.00 \pm 6.21$ & 0.977 \\
\hline Stillbirth rate, \% & $0.56 \pm 0.73$ & $0.67 \pm 0.87$ & 0.772 \\
\hline Birth weight, kg & $1.41 \pm 0.21$ & $1.43 \pm 0.22$ & 0.814 \\
\hline Weaning weight, $\mathrm{kg}$ & $6.01 \pm 0.62$ & $6.18 \pm 0.66$ & 0.586 \\
\hline Average daily gain, $\%$ & $218.60 \pm 21.92$ & $225.30 \pm 25.68$ & 0.559 \\
\hline
\end{tabular}

${ }^{1}$ Results were presented as mean \pm standard deviation. Values represent the means of 9 pens $(n=9)$ per treatment. 
Weaned piglets receiving VHE had significantly higher ADG during d 1-7 $(P=0.006)$ and 1-35 $(P=0.032)$ and better feed efficiency during d 22-35 $(P=0.026)$ and 1-35 $(P=0.020)$. In addition, there was a tendency for improved ADG $\mathrm{d}$ 8-21 $(P=0.068)$ and 22-35 ( $P=0.068)$, ADFI during d 1-7 $(P=0.068)$ and $1-35(P=0.091)$, and feed efficiency during d 1-7 $(P=0.067)$ in the VHE supplemented group (Table 4).

VHE supplementation had positive effects on the growth performance of weaned piglets, which was consistent with the findings of Charal et al. (2016). They reported that feeding lactating sows and to weaned piglets with anise oil containing diet could increase ADG, ADFI, and feed efficiency in weaned piglets. In addition, Oostindjer et al. (2010) noted that feeding sows and their weaned offspring with anise extract containing diet increased growth performance of their weaned offspring, which was related to the promotion of feed intake. As reported by Oostindjer et al. (2009), the supplementation of olfactory test substances in sows and their weaned offspring could establish the flavour continuity around weaning, thus affecting feed intake. Feeding sows with flavoured diets during late-gestation and lactation has been reported to make offspring preference on the same flavour feed, thus stimulating intake (Hepper et al., 2013). In this study, an increased tendency in ADFI in weaned piglets was observed, which could be partially linked to the increase in ADG. However, Oostindjer et al. (2010) showed that feeding flavoured diets to lactating sows and weaned piglets could reduce the stress around weaning in piglets. This could prevent the impairment of digestive and absorptive capacity induced by weaning events in pigs (Moeser et al., 2017). Sun et al. (2019) reported that feeding sows and their weaned offspring with anise oil containing diet improved nutrient

Table 4. Effects of supplementing a volatile herbal extract (VHE) mixture to the diet of weaned piglets on the growth performance of weaned pigs. ${ }^{1}$

\begin{tabular}{llll} 
& \multicolumn{2}{c}{ VHE, $\mathbf{~ m g / k g}$} & \\
\cline { 2 - 3 } Items & \multicolumn{1}{c}{$\boldsymbol{P}$-value } \\
Average daily gain, g & & 500 & \\
Days 1-7 & $215.00 \pm 23.17$ & $230.60 \pm 21.45$ & 0.006 \\
Days 8-21 & $393.00 \pm 43.11$ & $414.70 \pm 38.86$ & 0.068 \\
Days 22-35 & $514.50 \pm 72.51$ & $545.60 \pm 66.71$ & 0.068 \\
Days 1-35 & $406.00 \pm 46.39$ & $430.20 \pm 43.46$ & 0.032 \\
Average daily feed intake, g & & & \\
Days 1-7 & $240.30 \pm 24.17$ & $253.40 \pm 24.75$ & 0.068 \\
Days 8-21 & $501.60 \pm 64.95$ & $526.50 \pm 57.40$ & 0.155 \\
Days 22-35 & $741.70 \pm 88.99$ & $771.90 \pm 82.50$ & 0.149 \\
Days 1-35 & $494.60 \pm 51.80$ & $517.30 \pm 50.06$ & 0.091 \\
Gain to feed ratio & & & \\
Days 1-7 & $0.90 \pm 0.03$ & $0.91 \pm 0.02$ & 0.067 \\
Days 8-21 & $0.79 \pm 0.03$ & $0.79 \pm 0.02$ & 0.593 \\
Days 22-35 & $0.69 \pm 0.03$ & $0.71 \pm 0.02$ & 0.026 \\
Days 1-35 & $0.82 \pm 0.02$ & $0.83 \pm 0.02$ & 0.020
\end{tabular}

${ }^{1}$ Results were presented as mean \pm standard deviation. Values represent the means of 24 pens $(n=24)$ per treatment for average daily gain, average daily feed intake, gain to feed ratio. digestibility and feed efficiency in weaned piglets. Therefore, supplementing VHE to the diet of sows during late-gestation and lactation and supplementing their weaned offspring was beneficial to promote the feed intake and feed efficiency of the piglets through the establishment of flavour continuity, thus improving ADG. Moreover, the ingredients in the VHE could play a role in improving digestion, stress status at weaning and gut health (Yan and Kim, 2012; Wang et al., 2014; Diao et al., 2015; Williams et al., 2017; Yi et al., 2021).

\section{Conclusions}

This study confirmed that supplementing VHE to the diet of sows and their weaned offspring was beneficial to the growth performance of weaned piglets, but did not affect the reproductive performance of sows. This resulted in better ADG in the piglets during weaning, which can be economically beneficial to the swine industry.

\section{Acknowledgements}

The trial was supported through the Research-Focused Department Promotion Project as a part of the University Innovation Support Program for Dankook University in 2021 and the authors gratefully acknowledge the Center for Bio-Medical Engineering Core-Facility at Dankook University for providing reagents and equipment.

\section{Conflict of interest}

The authors confirm that there are no conflicts of interest associated with this publication.

\section{References}

Charal, J.W., Bidner, T.D., Southern, L.L. and Lavergne PAS, T.A., 2016. Effect of anise oil fed to lactating sows and nursery pigs on sow feed intake, piglet performance, and weanling pig feed intake and growth performance. The Professional Animal Scientist 32: 99-105. https://doi.org/10.15232/pas.2015-01433

Diao, H., Zheng, P., Yu, B., He, J., Mao, X., Yu, J., and Chen, D., 2015. Effects of benzoic acid and thymol on growth performance and gut characteristics of weaned piglets. Asian-Australasian Journal of Animal Sciences 28: 827-839. https://dx.doi.org/10.5713\%2Fajas.14.0704

Federation of Animal Science Societies (FASS), 2010. Guide for the care and use of agriculture animals in research and teaching. FASS, Champaign, IL, USA.

Hepper, P.G., Wells, D.L., Dornan, J.C. and Lynch, C., 2013. Long-term flavour recognition in humans with prenatal garlic experience. Developmental Psychobiology 55: 568-574. https://doi.org/10.1002/ dev.21059

Moeser, A.J., Pohl, C.S. and Rajput, M., 2017. Weaning stress and gastrointestinal barrier development: implications for lifelong gut health in pigs. Animal Nutrition 3: 313-321. https://doi. org/10.1016/j.aninu.2017.06.003 
Moon, J.H., 2017. effects of imprinting impacts through supplementation of star anise during pre- or postnatal period on performance of sows and their progeny. PhD thesis, Seoul National University, Seoul, South Korea.

National Research Council (NRC), 2012. Nutrient requirements of swine, $11^{\text {th }}$ revised edition. National Academies Press, Washington, DC, USA.

Oostindjer, M., Bolhuis, J.E., Mendl, M., Held, S., Van den Brand, H. and Kemp, B., 2011. Learning how to eat like a pig: effectiveness of mechanisms for vertical social learning in piglets. Animal Behaviour 82: 503-511. https://doi.org/10.1016/j.anbehav.2011.05.031

Oostindjer, M., Bolhuis, J.E., Van den Brand, H. and Kemp, B., 2009. Prenatal flavour exposure affects flavour recognition and stressrelated behaviour of piglets. Chemical Senses 34: 775-787. https:// doi.org/10.1093/chemse/bjp063

Oostindjer, M., Bolhuis, J.E., Van den Brand, H. and Kemp, B., 2010. Prenatal flavour exposure affects growth, health and behavior of newly weaned piglets. Physiology \& Behavior 99: 579-586. https:// doi.org/10.1016/j.physbeh.2010.01.031

Sun, H.Y., Lei, Y. and Kim, I., 2019. Effect of anise flavour on the performance of sows and their litters with different weaning ages. Korean Journal of Agricultural Science 46: 273-283. https://doi. org/10.7744/kjoas.20190013

Val-Laillet, D., Meurice, P. and Clouard, C., 2016. Familiarity to a feed additive modulates its effects on brain responses in reward and memory regions in the pig model. PLoS ONE 11: e0162660. https://doi.org/10.1371/journal.pone.0162660
Wang, H. and Kim, I.H., 2019. Influence of the efficacy of a probiotic complex containing Bacillus subtilis and Pichia farinosa on the growth performance and fecal microbiota of finishing pigs. Canadian Journal of Animal Science 99: 966-970. https://doi.org/10.1139/ cjas-2018-0226

Wang, L.S., Shi, Z., Shi, B.M. and Shan, A.S., 2014. Effects of dietary stevioside/rebaudioside A on the growth performance and diarrhoea incidence of weaned piglets. Animal Feed Science and Technology 187: 104-109. https://doi.org/10.1016/j.anifeedsci.2013.10.014

Williams, A.R., Hansen, T.V.A., Krych, L., Ahmad, H.F.B., Nielsen, D.S., Skovgaard, K. and Thamsborg, S.M., 2017. Dietary cinnamaldehyde enhances acquisition of specific antibodies following helminth infection in pigs. Veterinary Immunology and Immunopathology 189: 43-52. https://doi.org/10.1016/j.vetimm.2017.06.004

Yan, L. and Kim, I.H., 2012. Effect of eugenol and cinnamaldehyde on the growth performance, nutrient digestibility, blood characteristics, fecal microbial shedding and fecal noxious gas content in growing pigs. Asian-Australasian Journal of Animal Sciences 25: 1178-1183. https://dx.doi.org/10.5713\%2Fajas.2012.12111

Yi, Q., Liu, J., Zhang, Y., Qiao, H., Chen, F., Zhang, S. and Guan, W., 2021. Anethole attenuates enterotoxigenic Escherichia coli-induced intestinal barrier disruption and intestinal inflammation via modification of TLR signaling and intestinal microbiota. Frontiers in Microbiology 12: 647242. https://dx.doi. org/10.3389\%2Ffmicb.2021.647242 
